\title{
Impact of vaccination policy on changes in rubella virus antibody in Japanese pregnant women
}

\author{
M. Hanaoka ${ }^{1,2,3} \cdot$ K. Yamaguchi ${ }^{1}$ (D) $\cdot$ S. Yamaguchi ${ }^{3}$
}

Received: 14 November 2019 / Accepted: 1 July 2020 / Published online: 15 July 2020

(C) The Author(s) 2020

\begin{abstract}
Aim As a result of the 2012-2013 rubella epidemics in Japan, many cases of congenital rubella syndrome have been reported. Given the frequent changes to rubella vaccination policy in Japan, we investigated antibody prevalence among pregnant women according to birth year.

Subjects and methods Participants comprised 55,400 pregnant Japanese women for whom rubella-specific hemagglutination inhibition antibody had been measured during early pregnancy in our institute from 1987 to 2016. Birth year was considered for the 47,978 cases for which age was known.

Results The ratio of rubella antibody-negative cases among pregnant women born after 1962 decreased significantly with mandatory vaccination. In the transition phase, during which the administration target was changed from schoolgirls to children of both sexes (born 1979-1987) as temporary vaccination, the ratio of rubella antibody-negative pregnant women started increasing in the latter period of this phase. For generations born in or after 1988, the ratio of rubella antibody-negative pregnant women clearly increased when the vaccination target changed to non-mandatory vaccination of children of both sexes.

Conclusions Prevalence of antibody titers depends on vaccine coverage rates. Suitable information needs to be provided prior to conception to all women, their husbands, and family members.
\end{abstract}

Keywords Rubella $\cdot$ Vaccination $\cdot$ Immunization $\cdot$ Pregnancy $\cdot$ Low antibody titer $\cdot$ Congenital rubella syndrome

\section{Introduction}

Rubella infection is well known to generally cause mild illness with febrile rash in children and adults, but rubella infection early in pregnancy (particularly during the first 16 weeks) may result in miscarriage, stillbirth, or birth of an infant with birth defects due to congenital rubella syndrome (CRS) (CastilloSolórzano et al. 2011). The most important purpose of rubella vaccination is to prevent congenital rubella virus infections, including CRS.

K. Yamaguchi

yamaguchi-k@ncchd.go.jp

1 Center of Maternal-Fetal, Neonatal and Reproductive Medicine, National Center for Child Health and Development, 2-10-1 Okura, Setagaya, Tokyo 157-8535, Japan

2 Hanaoka IVF Clinic Shinagawa, Tokyo 141-0032, Japan

3 Yamaguchi Women's Hospital, Chiba 273-0031, Japan
Japan experienced multiple rubella epidemics in 20122013. As a result, the National Epidemiological Surveillance of Infectious Diseases received reports of about 15,000 cases of rubella and 43 cases of CRS between 2012 and 2014 (National Institute of Infectious Diseases, Japan 2014; Ujiie et al. 2014). Nationwide rubella epidemics had occurred around every 5 years in Japan until the early 2000s (1982, 1987-1988, and 1992-1993), with seasonal increases in spring and summer (National Institute of Infectious Diseases, Japan 2013a). Rubella vaccination for children of both sexes was included as routine immunization in April 1995. Since then, no nationwide epidemics have been reported (National Institute of Infectious Diseases, Japan 2003). Nationwide case-based surveillance for CRS was established in April 1999, and the sentinel surveillance system was introduced in January 2008. Very few rubella cases were reported until 2010, but some rubella cases were reported in 2011 among adult males in workplaces. A sharp increase in the number of reported rubella cases, to 2392, was seen in 2012, and the number of cases stayed high into 2013 (Centers for Disease Control and Prevention 2013). The World Health 
Organization US Region established the goal of eliminating rubella by 2010, and the European Region aimed to achieve the same goal by 2015 (Reef et al. 2011). Acceleration of rubella control and CRS prevention has been established as targets for the Western Pacific Region (World Health Organization 2012). Antibody titers against rubella virus are country-dependent and affected by the history of immunization in the country in addition to natural infections.

Elimination of rubella in Japan required a strategy to vaccinate susceptible individuals, and the history of immunizations against rubella in Japan is summarized Table 1 and Fig. 1 (Hanaoka et al. 2013). In 1977, the rubella vaccination program was started, targeting junior high school girls (girls, 1215 years old). In 1989, rubella vaccine started to be administered as the measles, mumps, and rubella (MMR) vaccine. In 1993, the MMR vaccination program was terminated in response to adverse effects of aseptic meningitis resulting from the mumps vaccine. Rubella vaccination was continued as a monovalent rubella vaccine until 1994. In 1995, rubella vaccination became non-mandatory and was provided to children of both sexes. This represented a transition phase for the target group from schoolgirls to children of both sexes and the monovalent rubella vaccination program for junior high school girls was continued to include boys. The target age was then expanded for un-inoculated targets. With these changes in vaccination policy, the coverage rate of rubella vaccination fell below that of many other countries (Gomi and Takahashi 2004; Takahashi et al. 2011). In 2006, measles-rubella (MR) vaccine was introduced as a two-dose vaccination, with the first administration at 1 year old, and the second at 5 or 6 years old (National Institute of Infectious Diseases, Japan 2006).

Since 1999, no significant rubella epidemics have been observed. Coverage rates with MMR and monovalent rubella vaccines thus seem to have been sufficient to prevent rubella among children of both sexes. However, in recent years, local rubella epidemics have been observed among young adults. In
2004, ten cases of CRS were reported (Kadoya et al. 1998; Ueda 2009). During 2012-2013, nationwide rubella epidemics occurred in Japan.

Reference of the antibody titer to test year is unsuitable for identifying vaccine-susceptible ages, so this study investigated the prevalence of rubella antibody among pregnant women according to birth year under the frequently changing rubella vaccination policy in Japan.

\section{Methods}

\section{Survey participants}

We studied 55,400 cases of Japanese pregnant women for whom rubella-specific hemagglutination inhibition antibody had been measured during early pregnancy (first trimester) in our institute for the 30-year period from 1987 to 2016. Within the 55,400 cases, year of birth was considered for the 47,978 cases in which the ages of the pregnant women were known.

\section{Hemagglutination inhibition (HI) test for measuring the rubella antibody titer}

The rubella-specific HI test was performed on U-bottom microtiter plates (Corning, NY, USA), with goose erythrocytes and the Baylor strain as the antigen. Serum was pretreated with $12.5 \%$ of kaolin in phosphate-buffered saline at 15 $25{ }^{\circ} \mathrm{C}$ for $20 \mathrm{~min}$, and adsorbed into $25 \%$ of goose erythrocytes at $4{ }^{\circ} \mathrm{C}$ for $60 \mathrm{~min}$ with occasional shaking. Two-fold serial diluted sera was incubated in $4 \mathrm{U}$ of hemagglutinin and $0.125 \%$ of goose erythrocytes at $15-25{ }^{\circ} \mathrm{C}$ for $60 \mathrm{~min}$.

Guidelines for obstetrical practice in Japan define HI antibody $\leq \times 16$ as a low antibody titer (Minakami et al. 2014). Titers of specific antibodies were determined at the final dilutions that completely inhibited hemagglutination. Rubella HI
Table 1 History of immunization against rubella virus in Japan

\begin{tabular}{|c|c|c|}
\hline Year & Target age (years) & Progress \\
\hline Up to 1976 & - & Vaccination unavailable \\
\hline 1977-1994 & $12-15$ & $\begin{array}{l}\text { Monovalent rubella vaccination program for junior high school } \\
\text { girls before pregnancy (girls only) }\end{array}$ \\
\hline 1989-1993 & $1-6$ & $\begin{array}{l}\text { MMR vaccination program for children of both sexes overlapping } \\
\text { with monovalent rubella vaccination program; started in } 1989 \\
\text { and terminated in } 1993 \text { because of adverse effects (aseptic } \\
\text { meningitis) from the mumps vaccine }\end{array}$ \\
\hline $1995-2003$ & $12-23$ & $\begin{array}{l}\text { Transition phase of target age from junior high school girls to } \\
\text { children of both sexes. The monovalent rubella vaccination } \\
\text { program for junior high school girls was continued while } \\
\text { including boys, then age was expanded for un-inoculated targets }\end{array}$ \\
\hline 1995-2005 & $1-7.5$ & Monovalent rubella vaccination program for children of both sexes. \\
\hline 2006 onwards & 1st: 1 2nd: 5-6 & MR vaccination program started for children of both sexes. \\
\hline
\end{tabular}


Fig. 1 History of immunization for rubella virus in Japan (each vaccine policy is shown): diagonal lines represent the birth year.

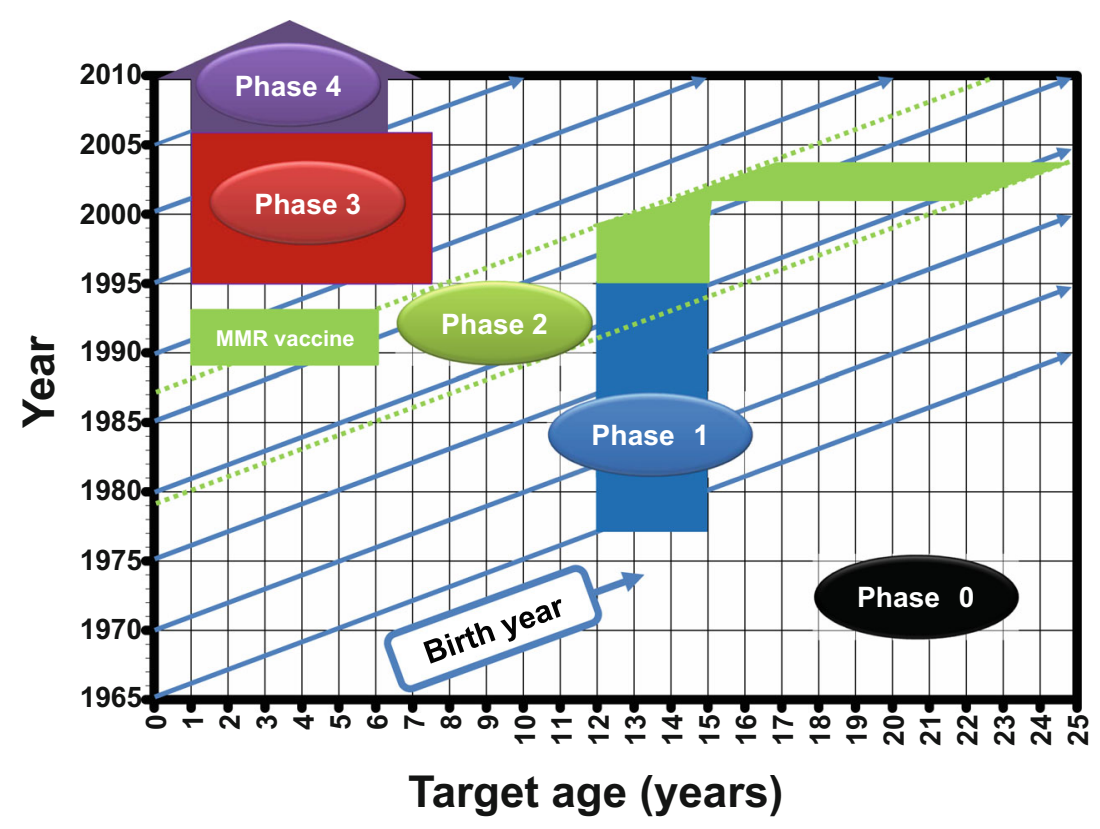

antibody titers of 1:16 are approximately equivalent to $30 \mathrm{IU} /$ ml (Terada et al. 2009).

\section{Variations in rubella vaccination policies}

In this study, we refer to the varied rubella vaccination policies as phases 0 through 4 (Table 2). In phase 0 , vaccination was unavailable. The rubella vaccine was first introduced in Japan in 1977. During phase 1, rubella vaccination was mandatory, but was administered only to schoolgirls (12-15 years old). During phase 2 , rubella vaccination was administered to school-age boys and girls, temporarily. During this time, the target of rubella vaccination was changed from schoolgirls to children of both sexes (1-6 years old). During phase 3, rubella vaccination was non-mandatory (but strongly recommended) and administered to children of both sexes as a single dose.
The present double-dose vaccination schedule (at 1 year old and 5-6 years old) represents phase 4 .

In 1994, major changes were made to Japanese immunisation laws (started in 1995), such that all childhood immunisations were no longer mandatory. Individuals would be given "strong recommendations" to undergo vaccination, but ultimately it would be their choice. The reason was mainly because of strong public opposition to the reinforcement of mandatory vaccination. Since then, the Japanese government has played a very passive role in the formulation of vaccine policies.

\section{Results}

With respect to the history of rubella vaccination in our country, we retrospectively investigated transitions in the actual prevalence of antibody in pregnant women.

Table 2 Each phase with born age and past history of immunization

\begin{tabular}{|c|c|c|c|c|c|c|}
\hline Phase & Era of birth & Policy & $\begin{array}{l}\text { Vaccination } \\
\text { target }\end{array}$ & Aim & $\begin{array}{l}\text { Dose } \\
\text { (coverage rate) }\end{array}$ & $\begin{array}{l}\text { Vaccination } \\
\text { method }\end{array}$ \\
\hline 0 & Up to 1961 & - & - & - & - & - \\
\hline 1 & $1962-1978$ & Mandatory & School-age girls & Prevention of CRS & 1 (approximately $70 \%$ ) & Targeted \\
\hline 2 & $1979-1987$ & $\begin{array}{l}\text { Non-mandatory } \\
\text { (strong recommendation) }\end{array}$ & $\begin{array}{l}\text { School-age children } \\
\text { of both sexes }\end{array}$ & $\begin{array}{l}\text { Prevention of CRS, } \\
\text { control of rubella }\end{array}$ & 1 & Targeted \\
\hline 3 & 1988-2004 & $\begin{array}{l}\text { Non-mandatory } \\
\quad \text { (strong recommendation) }\end{array}$ & Children of both sexes & Control of rubella & $1(50-60 \%)$ & Universal \\
\hline 4 & 2005 onwards & $\begin{array}{l}\text { Non-mandatory } \\
\quad \text { (strong recommendation) }\end{array}$ & Children of both sexes & Control of rubella & 2 (approximately $95 \%$ ) & Universal \\
\hline
\end{tabular}




\section{Baseline characteristics}

In the 1980 s, a total of 2341 cases were studied (mean age, $27.6 \pm 4.1$ years; range, $15-48$ years). In the 1990 s, a total of 8179 cases were studied (mean age, $27.8 \pm 4.0$ years; range, 16-47 years). In the 2000 s, a total of 17,876 cases were studied (mean age, $30.2 \pm 4.4$ years; range, $15-$ 46 years). In the 2010 s, a total of 16,930 cases were studied (mean age, $31.3 \pm 4.7$ years; age range, $15-48$ years). A significant increase in the ages of pregnant women was seen from the 1980 s to the 1990 s, from the 1990 s to the 2000 s, and from the 2000s to 2010 .

\section{Reference to test year}

Regarding the transition of antibody prevalence among pregnant women, the ratio of rubella antibody-negative (test plate values $<8$ by HI test) cases among pregnant women has decreased significantly since this study started in 1987 (Fig. 2a). Sufficient immunization, defined as under approximately $30 \%$ of patients showing a $16 \mathrm{HI}$ antibody titer, was achieved from 1996 to 2011 . The ratio started to increase in 2012.

\section{Reference to birth year}

In terms of antibody prevalence in pregnant women according to birth year, each phase showed characteristic changes (Fig. 2b). Phase 1 involved administration to schoolgirls before pregnancy (targets born 1962-1978). The ratio of rubella antibody-negative cases among pregnant women born after 1962 decreased significantly with vaccination of schoolgirls, which started in 1977 (Table 1). Phase 2 involved administration to school-aged boys and girls, temporarily. This phase represented a transition phase, during which time the administration target changed from schoolgirls to children of both sexes (targets born 1979-1987). Regarding the "trough generation" (transition phase) during which the target of vaccination changed from junior high school girls to children of both sexes, the ratio of rubella antibody-negative cases among pregnant women was clearly suggested to have increased in the latter period of this phase. Phase 3 involved administration to children of both sexes (targets born after 1988). As for generations born in or after 1988, as the time at which the target of vaccination was changed to children of both sexes, the ratio of rubella antibody-negative cases among pregnant women increased. Phase 4 represents the present double-dose vaccination schedule, as introduced in 2005 (not shown in figures).

The shift in rubella vaccination policy and targets from phase 1 (schoolgirls before pregnancy) to phase 3 (children of both sexes) was extremely complicated (Fig. 1). a

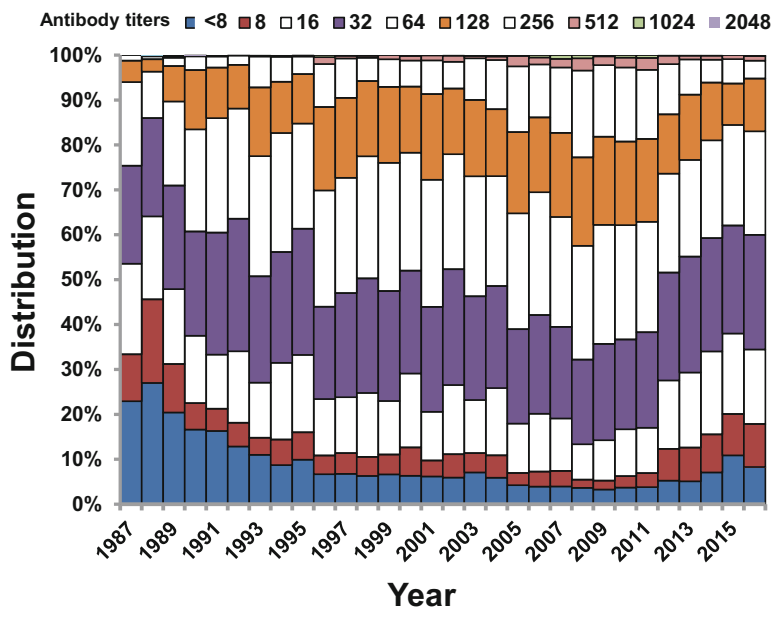

b

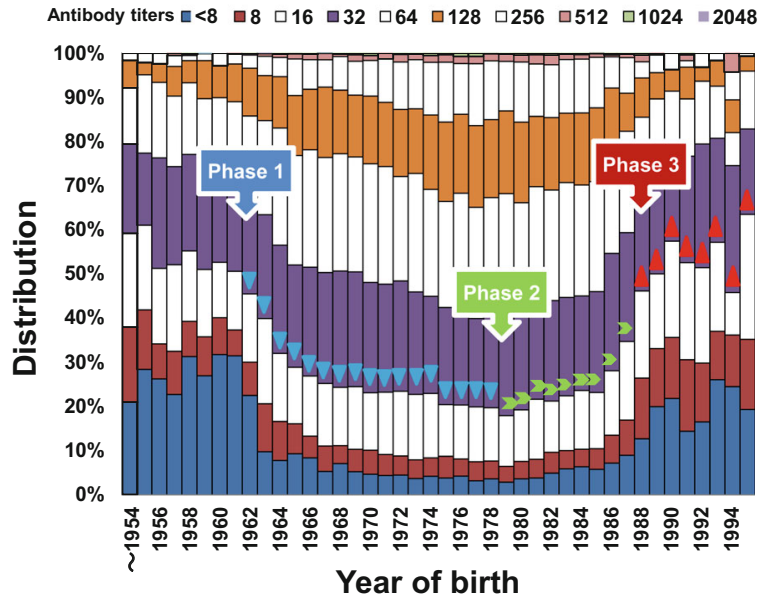

Fig. 2 a Changes in antibody titers according to test year. The ratio of rubella antibody-negative cases among pregnant women has decreased significantly since this study started in 1987 under the policy of vaccination for schoolgirls started in 1977. The ratio started to increase again from 2012. b Changes in antibody titers according to birth year. After the latter part of the transition phase (phase 2) during which the administration target was changed from schoolgirls to all children of both sexes, the ratio of rubella antibody-negative cases among pregnant women has been increasing

\section{Discussion}

A large number of cases of CRS were reported during the nationwide rubella epidemic in Japan, which was considered to have been caused mainly by this unique transition in vaccination policies in Japan. After the latter part of the transition phase (phase 2) during which the administration target changed from schoolgirls to children of both sexes, the ratio of rubella antibody-negative cases has been increasing among pregnant women.

In April 2014, in response to the outbreak occurring at the time, Japan's Ministry of Health, Labour and Welfare provided a guidance notification to healthcare authorities (National Institute of Infectious Diseases, Japan 2013b). That guidance provided information on rubella disease and CRS for pregnant 
women and their households, and encouraged vaccination for the family members of pregnant women (as rubella vaccination is contraindicated for pregnant women) and vaccination for women planning to get pregnant. CRS was classified as a Category $\mathrm{V}$ infectious disease requiring notification of all cases, and the Ministry set a goal of eliminating rubella by 2020 .

Although immunization against rubella among susceptible individuals is most effective, Japan has faced various challenges in implementing mass vaccination. More than 80 $90 \%$ of adults have already been immunized either by past vaccination or natural infection (National Institute of Infectious Diseases, Japan 2013a) and adults may thus be difficult to motivate, especially in the absence of an outbreak (Ujiie et al. 2014). In addition to routine immunization programs, adopting sero-surveillance is crucial to identify susceptible groups for targeted communication, to promote screening tests for antibody to identify individuals for selective vaccination, and, at the societal level, to encourage strong engagement of all stakeholders (including employers' associations) to support the national plan.

The most important purpose of rubella vaccination is to prevent congenital rubella virus infection, including CRS. We therefore retrospectively studied the transition of actual antibody prevalence among pregnant women. Our conclusion is that a large number of CRS cases were reported during the nationwide rubella epidemic in Japan, which is considered to have been attributable to this unique transition in vaccination policy in Japan. Once pregnant, women cannot receive the live rubella vaccine due to the infection risk to the fetus. The most important point is to provide necessary information including MR vaccination prior to conception to every woman planning to have a baby, as well as to her husband and family members.

Another problem, and a key limitation of this study, is that the most vulnerable group is young men, and many outbreaks therefore arise in workplaces. Most Japanese over 50 years old developed rubella in their youth and are immune. From January 1 to May 1 2013, a total of 5442 rubella cases were reported in Japan through the rubella surveillance system, with the majority (77\%) of cases occurring among adult males. This resurgence of rubella has mainly affected adult men born between 1962 and 1978, who had not received routine rubella vaccine during childhood, as only schoolgirls were vaccinated at that time, and men and women born aged 1979-1987, for whom vaccine coverage rates were relatively low (National Institute of Infectious Diseases, Japan 2013a). Further improvement of rubella control may be realized by providing adults with a chance to receive rubella vaccine, which may require collaboration with various stakeholders, including industry physicians.

Author contribution $\mathrm{MH}$ and $\mathrm{KY}$ designed the study, and wrote the manuscript. SY contributed to analysis and interpretation of data, and assisted in the preparation of the manuscript. All other authors have contributed to data collection and interpretation, and critically reviewed the manuscript. All authors approved the final version of the manuscript, and agree to be accountable for all aspects of the work in ensuring that questions related to the accuracy or integrity of any part of the work are appropriately investigated and resolved.

Funding sources This research did not receive any specific grant from funding agencies in the public, commercial, or not-for-profit sectors.

\section{Compliance with ethical standards}

Statement of ethics All patients provided informed consent for analysis of laboratory data and date of birth. All data were anonymized before analysis. This study method was approved by the ethics committee of Yamaguchi Hospital.

Disclosure statement The authors have no potential conflicts of interest to declare.

Open Access This article is licensed under a Creative Commons Attribution 4.0 International License, which permits use, sharing, adaptation, distribution and reproduction in any medium or format, as long as you give appropriate credit to the original author(s) and the source, provide a link to the Creative Commons licence, and indicate if changes were made. The images or other third party material in this article are included in the article's Creative Commons licence, unless indicated otherwise in a credit line to the material. If material is not included in the article's Creative Commons licence and your intended use is not permitted by statutory regulation or exceeds the permitted use, you will need to obtain permission directly from the copyright holder. To view a copy of this licence, visit http://creativecommons.org/licenses/by/4.0/.

\section{References}

Castillo-Solórzano C, Marsigli C, Bravo-Alcántara P, Flannery B, Ruiz Matus C, Tambini G, Gross-Galiano S, Andrus JK (2011) Elimination of rubella and congenital rubella syndrome in the Americas. J Infect Dis 204:571-578 https://doi.org/10.1093/infdis/ jir472

Centers for Disease Control and Prevention (CDC) (2013) Nationwide rubella epidemic - Japan, 2013. MMWR Morb Mortal Wkly Rep 62:457-462. https://www.cdc.gov/mmwr/pdf/wk/mm6223.pdf

Gomi H, Takahashi H (2004) Why is measles still endemic in Japan? Lancet 364:328-329. https://doi.org/10.1016/S0140-6736(04) 16715-9

Hanaoka M, Hisano M, Watanabe N, Sugawara K, Kambe Y, Kanda E, Sago H, Kato T, Yamaguchi K (2013) Changes in the prevalence of the measles, rubella, varicella-zoster, and mumps virus antibody titers in Japanese pregnant women. Vaccine 31:2343-2347. https://doi.org/10.1016/j.vaccine.2013.03.012

Kadoya R, Ueda K, Miyazaki C, Hidaka Y, Tokugawa K (1998) Incidence of congenital rubella syndrome and influence of the rubella vaccination program for schoolgirls in Japan 1981-89. Am J Epidemiol 148:263-268. https://doi.org/10.1093/oxfordjournals. aje.a009634

Minakami H, Maeda T, Fujii T et al (2014) Guidelines for obstetrical practice in Japan: Japan Society of Obstetrics and Gynecology (JSOG) and Japan Association of Obstetricians and Gynecologists(JAOG) 2014 edition. J Obstet Gynaecol Res 40: 1469-1499. https://doi.org/10.1111/jog.13831 
National Institute of Infectious Diseases, Japan (2003) Rubella, Japan, 1999-2002. Infect Agents Surveill Rep 24:53-54. http://idsc.nih. go.jp/iasr/24/277/tpc277.html

National Institute of Infectious Diseases, Japan (2006) Measles and rubella in Japan, as of march 2006. Infect Agents Surveill Rep 27:8586. http://idsc.nih.go.jp/iasr/27/314/tpc314.html

National Institute of Infectious Diseases, Japan (2013a) Guidance on strengthening measures for prevention and control of rubella and congenital rubella syndrome. Infect Agents Surveill Rep 34:90. https://www.niid.go.jp/niid/en/iasr-sp/2250-related-articles/relatedarticles-398/3427-de3981.html

National Institute of Infectious Diseases, Japan (2013b) Rubella and congenital rubella syndrome in Japan, as of March 2013. Infect Agents Surveill Rep 34:87-89. https://www.niid.go.jp/niid/en/basicscience/865-iasr/3469-tpc398.html

National Institute of Infectious Diseases, Japan (2014) Prompt report of rubella, as of March 5, 2014. Infectious Diseases Weekly Report 2014. https://www.niid.go.jp/niid/en/index-e/865-iasr/7944-457te.html

Reef SE, Strebel P, Dabbagh A, Gacic-Dobo M, Cochi S (2011) Progress toward control of rubella and prevention of congenital rubella syndrome-worldwide, 2009. J Infect Dis 204:S24-S27. https://doi. org/10.1093/infdis/jir155
Takahashi K, Ohkusa Y, Kim JY (2011) The economic disease burden of measles in Japan and a benefit cost analysis of vaccination: a retrospective study. BMC Health Serv Res 11:254. https://doi.org/10. 1186/1472-6963-11-254

Terada K, Inoue M, Wakabayashi T, Ogita S, Ouchi K (2009) What EIA assay levels correspond to rubella antibody $\mathrm{HI}$ assay titer [Article in Japanese]. Kansenshogaku Zasshi 83:26-30. https://doi.org/10. 11150/kansenshogakuzasshi.83.26

Ueda K (2009) Development of the rubella vaccine and vaccination strategy in Japan. Vaccine 27:3232-3233. https://doi.org/10.1016/j. vaccine.2009.02.076

Ujiie M, Nabae K, Shobayashi T (2014) Rubella outbreak in Japan. Lancet 383:1460-1461. https://doi.org/10.1016/S0140-6736(14) 60712-1

World Health Organization (2012) Elimination of measles and acceleration of rubella control. Regional Committee for the Western Pacific. Resolution WPR/RC63.5. World Health Organization, Hanoi, Vietnam. http://www.wpro.who.int/about/regional committee/63/ resolutions/wpr_rc63_r5_measles_elimination_03oct.pdf

Publisher's note Springer Nature remains neutral with regard to jurisdictional claims in published maps and institutional affiliations. 